\title{
Early Non-invasive Detection of Acute 1,2-Dichloroethane- induced Toxic Encephalopathy in Rats
}

\author{
XIAOLIANG ZHOU ${ }^{1}$, YUZE CAO ${ }^{1}$, CHRISTOPH LEUZE $^{2}$, BINBIN NIE $^{3}$, BAOCI SHAN ${ }^{3}$, \\ WENBIN ZHOU ${ }^{1}$, PETER CIPRIANO ${ }^{2}$ and BO XIAO $^{1}$ \\ ${ }^{1}$ Department of Neurology, Xiangya Hospital, Central-South University, Changsha, P.R. China; \\ ${ }^{2}$ Richard M.Lucas Center for Imaging, Department of Radiology, Stanford, CA, U.S.A.; \\ ${ }^{3}$ Key Laboratory of Nuclear Analytical Techniques, Institute of High Energy Physics, \\ Chinese Academy of Sciences, Beijing, P.R. China
}

\begin{abstract}
Aim: To assess the acute effect of 1,2dichloroethane (1,2-DCE) on rat brain using diffusion magnetic resonance imaging (dMRI). Materials and Methods: We performed dMRI on 30 male Sprague-Dawley rats, microstructural alterations were investigated by calculating the mean fractional anisotropy (FA) and apparent diffusion coefficient $(A D C)$ changes in eight selected brain regions of interest. For the whole brain, clusters of 20+ voxels that differed significantly in FA and $A D C$ between groups were marked. Hematoxylin-eosin staining was performed to confirm pathological changes. Results: Brain images showed lesions with brain edema in the white matter in both hemispheres in all groups exposed to 1,2-DCE. Diffusivity values were significantly different after 1,2-DCE inhalation ( $p<0.05)$. Conclusion: Primarily cytotoxic edema occurred in acute 1,2-DCE-induced brain edema in rats. dMRI could be used for the early noninvasive detection of acute 1,2-DCE-induced toxic encephalopathy.
\end{abstract}

1,2-Dichloroethane (1,2-DCE) is a toxic chemical widely used in the production of vinyl chloride. In a 1982 National Occupational Exposure Survey conducted by the United States National Institute for Occupational Safety and Health, $28 \%$ of employees working with adhesives and solvents were found to be exposed to 1,2-DCE (1).

This article is freely accessible online.

Correspondence to: Bo Xiao, Department of Neurology, Xiangya Hospital, Central-South University, 87 Xiangya Road, Changsha, Hunan 410008, P.R. China. Tel: +86 073184327236, Fax: +86 073184327332,e-mail:xiaobo62xy@126.com

Key Words: 1,2-Dichloroethane exposure, diffusion magnetic resonance imaging, brain edema, toxic encephalopathy.
Toxic encephalopathy with intracranial hypertension and cerebral edema is a characteristic feature of acute and subacute 1,2-DCE intoxication (2-5). Once toxic encephalopathy is suspected, expedited non-invasive diagnosis could ensure effective treatment.

Diffusion magnetic resonance imaging (dMRI) allows for the early non-invasive characterization of biological tissues based on their water diffusion characteristics (6). Measuring changes in diffusivity as determined by dMRI is a promising method for characterizing microstructural changes or differences in neuropathology, including edema (7).

In disease studies, a decrease in fractional anisotropy (FA) value is often interpreted as a loss of microstructural integrity. The apparent diffusion coefficient (ADC) is a measure of the rate of water diffusion. Measurements of the mean ADC value have been used to detect edema (8). A decreased mean ADC value can result from restricted diffusion by intracellular water accumulation (e.g. cytotoxic edema). In contrast, an increased mean ADC value may result from free diffusion by increased extracellular space (e.g. vasogenic edema) (9).

A detailed dMRI study on the effect of 1,2-DCE on rat brain would greatly increase the understanding of the possible negative effects of 1,2-DCE exposure and provide significant information on the use of dMRI for the early noninvasive detection of 1,2-DCE-induced toxic encephalopathy.

\section{Materials and Methods}

Animal model. Experiments involving animals adhered to the Guiding Principles in the Care and Use of Animals approved by the Council of the American Physiological Society (10). All experimental protocols were approved by the Animal Ethics Committee of Central South University, Changsha, China (SYXK2011-0001). The animals were treated humanely at all times, and all possible steps were taken to avoid animal suffering at each stage of the experiment. 
Thirty male Sprague-Dawley rats (190-230 g) were randomly assigned to five groups (six rats per group) exposed to different amounts of 1,2-DCE in a HOPE-MED8050 automatic dynamic inhalation chamber (Tianjin Hope Industry\& Trade Co.Ltd, China) (11). Group 1 was exposed to $4 \mathrm{~g} / \mathrm{m}^{3}$ for $1.5 \mathrm{~h}$, group 2 to $4 \mathrm{~g} / \mathrm{m}^{3}$ for $4 \mathrm{~h}$, group 3 to $12 \mathrm{~g} / \mathrm{m}^{3}$ for $1.5 \mathrm{~h}$, and group 4 to $12 \mathrm{~g} / \mathrm{m}^{3}$ for $4 \mathrm{~h}$. The control group was placed in a chamber for 4 hours but not exposed to $1,2-\mathrm{DCE}$.

The 1,2-DCE solution (high performance liquid chromatographygrade; Bellancom Chemistry Co.Ltd, Beijing, China) was weighed according to the administered concentration. A feedback system measuring 1,2-DCE concentrations in air samples taken constantly from the chamber adjusted the air valve and pump in order to maintain the desired ratio of 1,2-DCE to air. The actual exposure was: $3.95 \pm 0.33 \mathrm{~g} / \mathrm{m}^{3}, 3.97 \pm 0.25 \mathrm{~g} / \mathrm{m}^{3}, 11.25 \pm 0.33 \mathrm{~g} / \mathrm{m}^{3}$ and $11.75 \pm 0.20 \mathrm{~g} / \mathrm{m}^{3} 1,2$-DCE in groups $1-4$ respectively. The chamber was also controlled for oxygen content, air pressure, humidity and temperature, which was maintained at $22 \pm 2^{\circ} \mathrm{C}$.

We recorded the animals' behavior when they were exposed to 1,2-DCE, and we performed MRI and dMRI on the third day after the rats were taken out of the exposure chamber.

Imaging protocol. Scans were acquired on a Bruker Biospec 7.0T MRI scanner using a whole-body gradient coil with a maximum gradient strength of $440 \mathrm{mT} / \mathrm{m}$. Animals were anesthetized with $3 \%$ chloral hydrate $(0.8 \mathrm{ml} / \mathrm{kg}$, injected intraperitoneally) and anchored with ear bars in a prone position on the scanning bed. Scans were acquired using a custom-built rat head coil with the following protocols: i) Rapid acquisition with relaxation enhancementinversion recovery sequence (RARE-IR-T1): Axial slices with field of view (FOV) of $3.5 \times 3.5 \mathrm{~cm}$, matrix size of $128 \times 128$ and a thickness of $1 \mathrm{~mm}$ without gap were acquired covering the whole brain. The flip angle was $180^{\circ}$. Timing parameters were repetition time $(\mathrm{TR})=3000 \mathrm{~ms}$, echo time $(\mathrm{TE})=10 \mathrm{~ms}$ and inversion time $(\mathrm{TI})=900 \mathrm{~ms}$. The total acquisition time of the T1-weighted scan was $19 \mathrm{~m} 12 \mathrm{~s}$. ii) Turbo-RARE T2-weighted scan: The geometry and placement of slices were as for the T1-weighted scan described in (i). The timing parameters were $\mathrm{TR}=2500 \mathrm{~ms}, \mathrm{TE}=33 \mathrm{~ms}$ and a total acquisition time of $1 \mathrm{~min} 20 \mathrm{~s}$. iii) dMRI with echo-planar imaging (EPI) readout: The geometry and placement of slices were is for the T1-weighted scan described in (i). The timing parameters were $\mathrm{TR}=5500 \mathrm{~ms}, \mathrm{TE}=26 \mathrm{~ms}$, diffusion time $\Delta=14 \mathrm{~ms}$, diffusion pulse duration $\delta=3 \mathrm{~ms}$, b-value $b=1,800 \mathrm{~s} / \mathrm{mm}^{2}$. The diffusion gradients were applied in 30 non-colinear directions.

Data analysis. We used the statistical parametric mapping (SPM)compatible diffusion tensor imaging (DTI) toolbox that incorporates intensive multi-contrast image registration to prospectively determine FA alterations.

The diffusion-weighted images were linearly registered to the volume taken without diffusion weighting using DTIStudio (12) to compensate for motion. DTIStudio was then used to calculate FA and ADC values. All the normalized FA and ADC images were resliced to $1.0 \times 1.0 \times 1.5 \mathrm{~mm}^{3}$ voxels (after zooming). The resliced images were smoothed with a Gaussian kernel of $2.0 \times 2.0 \times 4.0 \mathrm{~mm}^{3}$ voxels (after zooming).

Eight regions of interest (ROIs) were selected from the atlas in Paxinos and Watson space (13): the internal capsule, midbrainperiaqueductal gray matter (GM), hypothalamus, cerebellumcerebellar nucleus, cingulate gyrus, hippocampus, sensory cortex and motor cortex. The mean FA and ADC of each ROI were extracted from the smoothed individual images. Results are presented as the mean \pm standard deviation (SD), and analysis was performed with Stata 20 (StataCorp, College Station, TX, USA). The results were evaluated by analysis of variance (ANOVA). A level of $p<0.05$ was considered significant.

For the whole brain, clusters of $20+$ voxels that significant differed in FA and ADC $(p<0.005)$ between groups were marked. Statistical analysis was performed with SPM8 (Wellcome Department of Cognitive Neurology, London, UK) and the toolbox spmratIHEP (13). The data were first spatially normalized to allow voxel-wise comparison between animals. Two-sample $t$-tests were performed between groups. The critical $t$-value was $3.169[t(10)=3.169$, $p=0.005]$.

For fiber tractography, three ROIs were selected from the original FA images of each rat. The ROIs covered the cerebellum-cerebellar nucleus, the internal capsule and the midbrain-periaqueductal GM. Fibers were tracked using MedINRIA (14) and all tracts running through these ROIs of each individual were used for statistical evaluation. Stata 20 was used to calculate the mean number of fibers and the SD of each group. Group comparison was again performed using two-sample $t$-test between the groups.

After MRI scanning, the rats were sacrificed under deep anesthetization (3\% chloral hydrate, $1.2 \mathrm{ml} / \mathrm{kg}$, injected intraperitoneally) and brain tissue was collected. Tissue blocks that corresponded to selected layers from ROIs in MRI were cut at $5 \mu \mathrm{m}$ thickness for hematoxylin-eosin (HE) staining in order to confirm pathological changes.

\section{Results}

The rats were sedated during the first $24 \mathrm{~h}$ following exposure and slowly returned to normal activity from the second day. The control group exhibited a normal level of activity throughout the experiment.

All the T1-weighted images (T1WI), T2-weighted images (T2WI), and HE staining showed lesions in the white matter (WM) in the rats exposed to 1,2-DCE. Figure 1 shows the T1WI and T2WI in different regions of the control group (Figure 1a and c) and the rats exposed to 1,2-DCE (Figure $1 \mathrm{~b}$ and $\mathrm{d}$ ). The T1WI and T2WI of rats exposed to 1, 2-DCE revealed lesions with brain edema in the WM in both hemispheres, which were not observed in the control group. The strongest affected regions were the lateral ventricle and dentate nuclei. Pathological confirmation was performed with HE staining, which also showed obvious brain edema in the rats exposed to 1,2-DCE (Figure 2).

For the eight designated ROIs, mean FA and ADC values differed between different ROIs. The mean ADCs for the internal capsule, midbrain-periaqueductal GM and cerebellum-cerebellar nucleus were lowest in group 2. ADCs in the hypothalamus, cingulate gyrus, hippocampus, sensory cortex and motor cortex were lowest in group $3(p<0.05)$ (Table I).

FA values in the experimental groups were lower than those of the control group. The FA value for the internal capsule was lowest in group $4(p<0.05)$. The FA values 


\section{Cerebellum Periventricular Periventricular Periventricular}

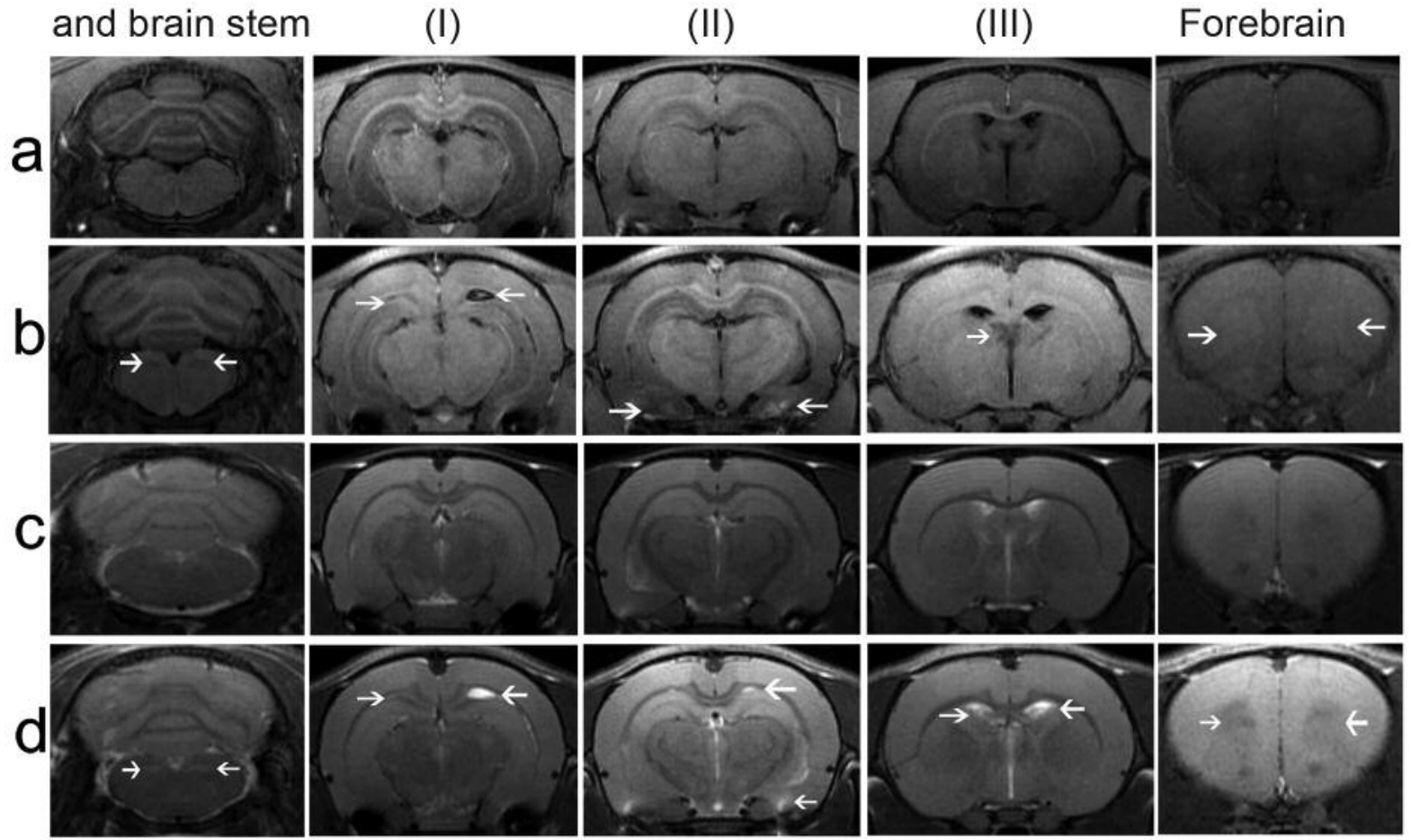

Figure 1. Brain Images T1-weighted $(a, b)$ and T2-weighted $(c, d)$ images of a single rat from the control group $(a, c)$ and the 1,2-dichloroethanetreated group $(b, d)$. There are lesions with diffuse brain edema in the white matter in both hemispheres. The lateral ventricle and dentate nuclei are the most affected areas (arrows).

decreased with time in the hypothalamus, cingulate gyrus and sensory cortex; there was a dose-dependent effect in all ROIs except for the hippocampus $(p<0.05)$ (Table II).

For the voxel-based changes in the whole brain, many regions in the brains of rats of groups exposed to 1,2-DCE were observed to have FA and ADC values lower than those in the control group, while groups 3 and $4\left(12 \mathrm{~g} / \mathrm{m}^{3} 1,2\right.$ DCE) had more regions with higher ADC values than did groups 1 and 2 ( $4 \mathrm{~g} / \mathrm{m}^{3}$ groups). The upper panel of Figure $3 \mathrm{a}$ and $\mathrm{b}$ show maximum intensity projections (MIP) of the statistical results of the comparison of the control group and group 1 (height threshold $\mathrm{T}=3.17$, extent threshold $\mathrm{k}=20$ voxels) acquired with spmratIHEP projected on a sagittal, coronal and axial slice of a transparent rendering of the rat brain. The colored regions in the lower panel of Figure 3a show the areas with significantly lower ADC values in group 1 compared to the control group; the colored regions in the lower panel of Figure $3 \mathrm{~b}$ show the areas with significantly lower FA values in group 1.

The most striking result was the greater number of fiber tracts in the control group compared to the groups exposed to 1,2-DCE (Figure 4a). Some subtle differences in the fiber tracking data were observed for the other groups with a general trend for a decrease in the number of fiber tracts with increasing 1,2-DCE exposure. The streamline diffusion tensor tractography of the control group is shown in Figure $4 \mathrm{~b}$.

\section{Discussion}

In order to establish an animal model of 1,2-DCE-induced toxic encephalopathy, we used the dynamic inhalation chamber setup, which provides enough fresh air to prevent acute hypoxia. Another advantage of this chamber is that exposure takes place during inhalation, which is the most common way humans are exposed (15).

The median lethal dose for an 8-h exposure to 1,2-DCE in rats was determined to be $1,000 \mathrm{ppm}\left(4 \mathrm{~g} / \mathrm{m}^{3}\right)$. A single $7-\mathrm{h}$ exposure at 3,000 ppm $\left(12 \mathrm{~g} / \mathrm{m}^{3}\right)$ 1,2-DCE caused death in rats. Exposure to lower concentrations of 1,2-DCE for longer periods did not appear to produce neurological effects (15). We chose higher doses for the exposures to create this animal model of 1,2-DCE-induced toxic encephalopathy.

Breathing 1,2-DCE induced central nervous system depression. This depression on some rats was reversible after 

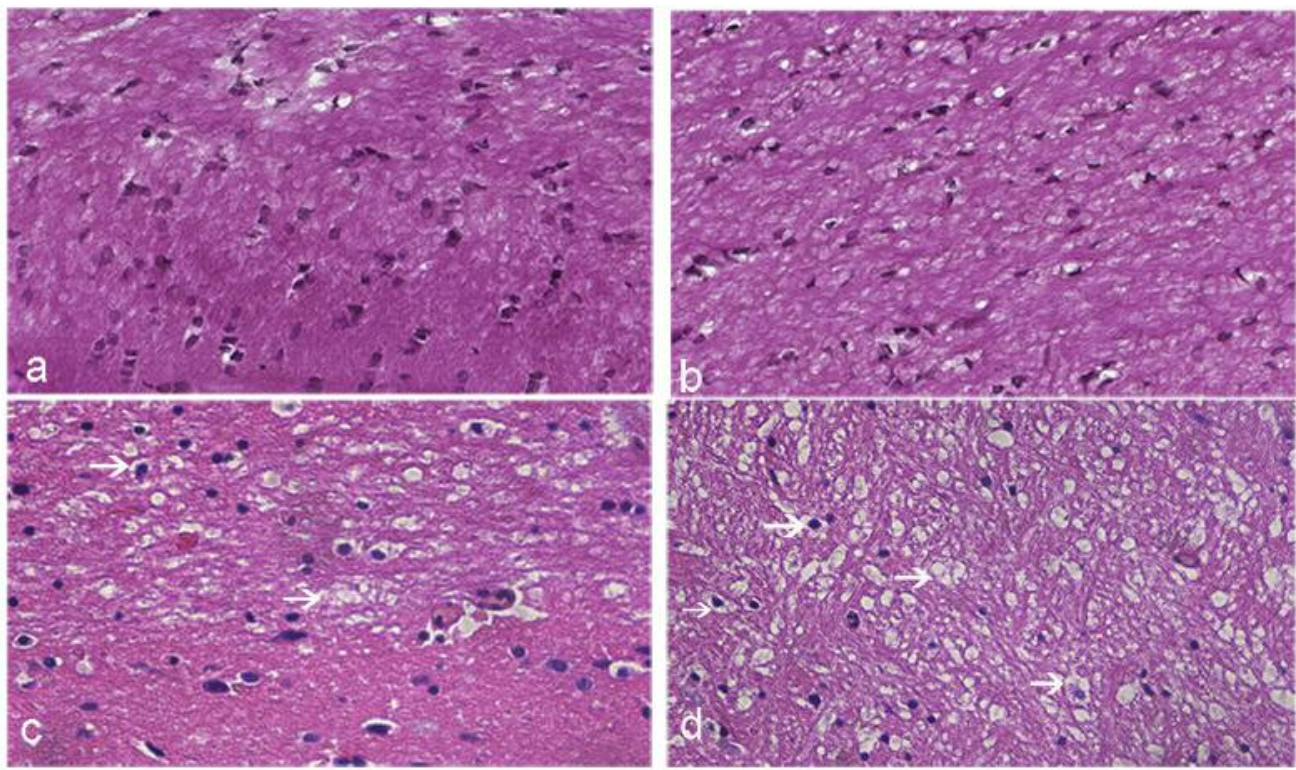

Figure 2. Compared to the control rat $(a, b)$, the hematoxylin-eosin staining of brain tissues from 1,2-dichloroethane-treated rats in group $4(c, d)$ showed severe brain edema (arrows). Parts a and $c$ were located at the posterior-lateral area of the lateral ventricles, and parts $b$ and $d$ were from the anteromedial area of the lateral ventricles. Original magnification $\times 100$.

Table I. Analysis of variance of mean apparent diffusion coefficient (ADC) values for different regions of interest (ROI). F and p-values are provided where there was a significant difference in the ROI $(p<0.05)$.

\begin{tabular}{|c|c|c|c|c|c|c|c|c|c|c|c|}
\hline \multirow[b]{2}{*}{ ROI } & \multicolumn{5}{|c|}{ Mean $\mathrm{ADC} \pm \mathrm{SD}$} & \multicolumn{2}{|c|}{ Duration effect } & \multicolumn{2}{|c|}{ Dose effect } & \multicolumn{2}{|c|}{$\begin{array}{l}\text { Duration } \times \\
\text { dose-effect }\end{array}$} \\
\hline & Control group & Group 1 & Group 2 & Group 3 & Group 4 & F-Value & $p$-Value & F-Value & $p$-Value & F-Value & $p$-Value \\
\hline Internal capsule & $\begin{array}{l}2.55 \mathrm{E}-04 \pm \\
2.48 \mathrm{E}-06\end{array}$ & $\begin{array}{c}2.50 \mathrm{E}-04 \pm \\
1.82 \mathrm{E}-06\end{array}$ & $\begin{array}{l}2.33 \mathrm{E}-04 \pm \\
4.24 \mathrm{E}-05\end{array}$ & $\begin{array}{c}2.58 \mathrm{E}-04 \pm \\
4.05 \mathrm{E}-06\end{array}$ & $\begin{array}{c}2.59 \mathrm{E}-04 \pm \\
5.01 \mathrm{E}-06\end{array}$ & & & & & & \\
\hline $\begin{array}{l}\text { Midbrain-periaqueductal } \\
\text { GM }\end{array}$ & $\begin{array}{l}2.96 \mathrm{E}-04 \pm \\
1.06 \mathrm{E}-05\end{array}$ & $\begin{array}{l}2.87 \mathrm{E}-04 \pm \\
1.98 \mathrm{E}-05\end{array}$ & $\begin{array}{l}2.73 \mathrm{E}-04 \pm \\
6.71 \mathrm{E}-05\end{array}$ & $\begin{array}{l}2.99 \mathrm{E}-04 \pm \\
1.57 \mathrm{E}-05\end{array}$ & $\begin{array}{l}3.06 \mathrm{E}-04 \pm \\
1.36 \mathrm{E}-05\end{array}$ & & & & & & \\
\hline Hypothalamus & $\begin{array}{l}3.48 \mathrm{E}-04 \pm \\
9.00 \mathrm{E}-06\end{array}$ & $\begin{array}{l}2.71 \mathrm{E}-04 \pm \\
7.49 \mathrm{E}-06\end{array}$ & $\begin{array}{c}2.68 \mathrm{E}-04 \pm \\
3.53 \mathrm{E}-06\end{array}$ & $\begin{array}{l}2.61 \mathrm{E}-04 \pm \\
5.42 \mathrm{E}-06\end{array}$ & $\begin{array}{l}2.76 \mathrm{E}-04 \pm \\
8.66 \mathrm{E}-06\end{array}$ & 4.36 & 0.0470 & 226.95 & 0.0000 & 10.03 & 0.0040 \\
\hline $\begin{array}{l}\text { Cerebellum-cerebellar } \\
\text { nucleus }\end{array}$ & $\begin{array}{c}3.45 \mathrm{E}-04 \pm \\
3.59 \mathrm{E}-06\end{array}$ & $\begin{array}{l}3.45 \mathrm{E}-04 \pm \\
3.95 \mathrm{E}-05\end{array}$ & $\begin{array}{c}3.03 \mathrm{E}-04 \pm \\
3.85 \mathrm{E}-05\end{array}$ & $\begin{array}{c}3.50 \mathrm{E}-04 \pm \\
3.95 \mathrm{E}-06\end{array}$ & $\begin{array}{c}3.55 \mathrm{E}-04 \pm \\
1.45 \mathrm{E}-05\end{array}$ & & & 4.37 & 0.0236 & 4.80 & 0.0368 \\
\hline Cingulate gyrus & $\begin{array}{l}2.66 \mathrm{E}-04 \pm \\
3.46 \mathrm{E}-06\end{array}$ & $\begin{array}{l}2.52 \mathrm{E}-04 \pm \\
7.92 \mathrm{E}-06\end{array}$ & $\begin{array}{l}2.48 \mathrm{E}-04 \pm \\
7.73 \mathrm{E}-06\end{array}$ & $\begin{array}{l}2.40 \mathrm{E}-04 \pm \\
7.53 \mathrm{E}-06\end{array}$ & $\begin{array}{l}2.68 \mathrm{E}-04 \pm \\
1.56 \mathrm{E}-05\end{array}$ & 9.61 & 0.0047 & & & 17.05 & 0.0004 \\
\hline Hippocampus & $\begin{array}{l}2.91 \mathrm{E}-04 \pm \\
2.21 \mathrm{E}-06\end{array}$ & $\begin{array}{l}2.75 \mathrm{E}-04 \pm \\
9.95 \mathrm{E}-06\end{array}$ & $\begin{array}{c}2.69 \mathrm{E}-04 \pm \\
4.09 \mathrm{E}-06\end{array}$ & $\begin{array}{c}2.62 \mathrm{E}-04 \pm \\
1.97 \mathrm{E}-06\end{array}$ & $\begin{array}{l}2.77 \mathrm{E}-04 \pm \\
1.10 \mathrm{E}-05\end{array}$ & & & 12.64 & 0.0002 & 12.91 & 0.0014 \\
\hline Sensory cortex & $\begin{array}{l}2.65 \mathrm{E}-04 \pm \\
5.94 \mathrm{E}-06\end{array}$ & $\begin{array}{l}2.53 \mathrm{E}-04 \pm \\
7.25 \mathrm{E}-06\end{array}$ & $\begin{array}{c}2.52 \mathrm{E}-04 \pm \\
1.08 \mathrm{E}-05\end{array}$ & $\begin{array}{l}2.48 \mathrm{E}-04 \pm \\
5.65 \mathrm{E}-06\end{array}$ & $\begin{array}{l}2.53 \mathrm{E}-04 \pm \\
9.15 \mathrm{E}-06\end{array}$ & & & 4.92 & 0.0158 & & \\
\hline Motor cortex & $\begin{array}{c}2.60 \mathrm{E}-04 \pm \\
4.27 \mathrm{E}-06\end{array}$ & $\begin{array}{l}2.62 \mathrm{E}-04 \pm \\
1.21 \mathrm{E}-05\end{array}$ & $\begin{array}{c}2.70 \mathrm{E}-04 \pm \\
4.59 \mathrm{E}-06\end{array}$ & $\begin{array}{c}2.57 \mathrm{E}-04 \pm \\
4.23 \mathrm{E}-06\end{array}$ & $\begin{array}{l}2.64 \mathrm{E}-04 \pm \\
2.35 \mathrm{E}-05\end{array}$ & & & & & & \\
\hline
\end{tabular}

GM: Gray matter.

exposure. Our results were similar to those observed in adult Fischer rats (16).

Clinical articles have reported extensive edematic lesions in cerebellar, bilateral WM, basal ganglia and thalami $(2,3)$.
The hypothalamus responds to toxic exposure by initiating a certain firing pattern (17). The cerebral cortex, midbrain, cingulate gyrus and hippocampus have been reported to be involved in toxic encephalopathies (18-20). 

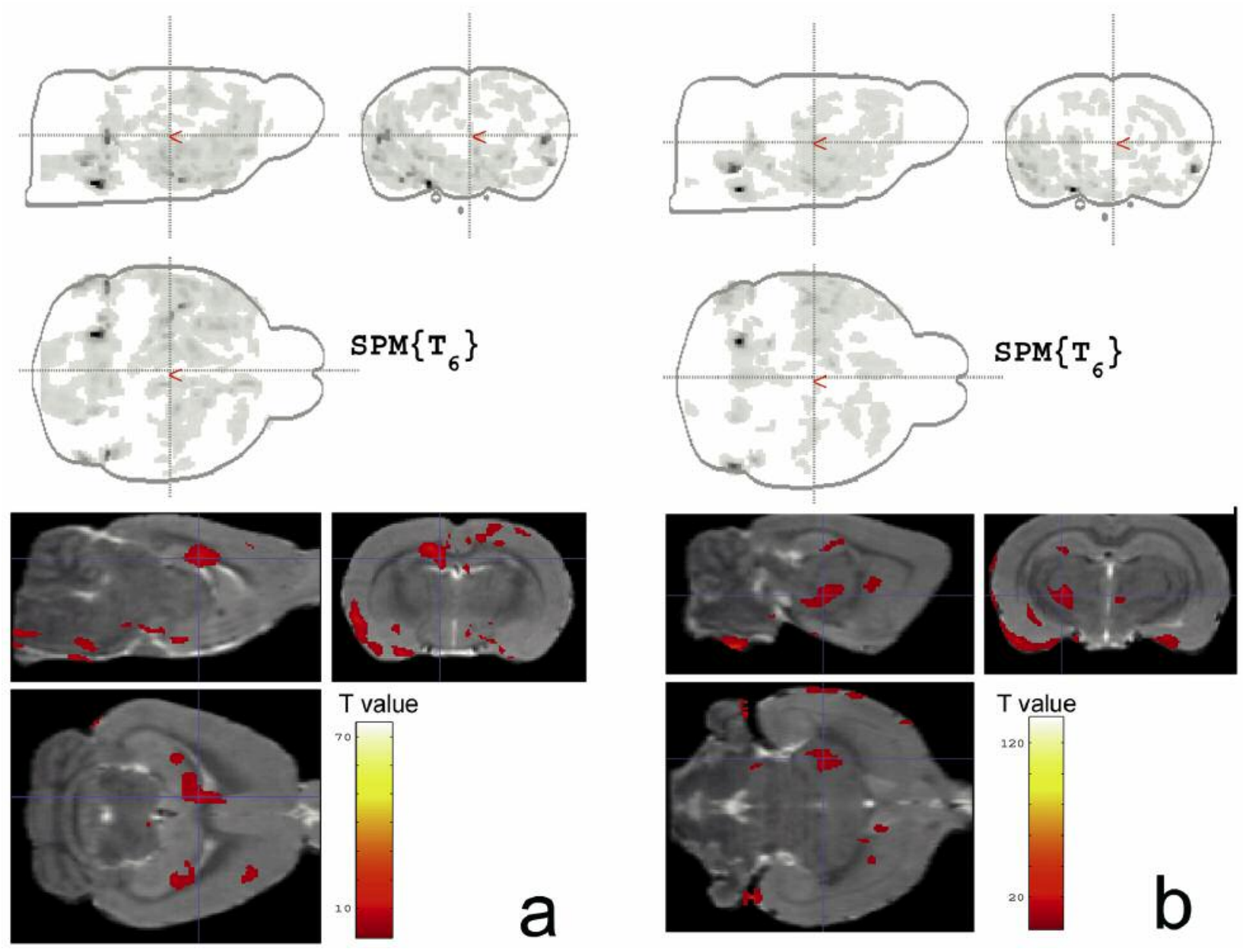

Figure 3. The SPMratIHEP results of the comparison between brain of a rat in the control group and in group 1. The upper panel shows apparent diffusion coefficient $(A D C)(a)$, and the fractional anisotropy $(F A)(b)$ results displaying the maximum intensity projections on the transparent brain in three orthogonal planes. The lower panel lower shows areas with significantly decreased ADC (a) and FA (b) values in regions of interest in group 1 compared to the control group. The color scale represents the T-value.
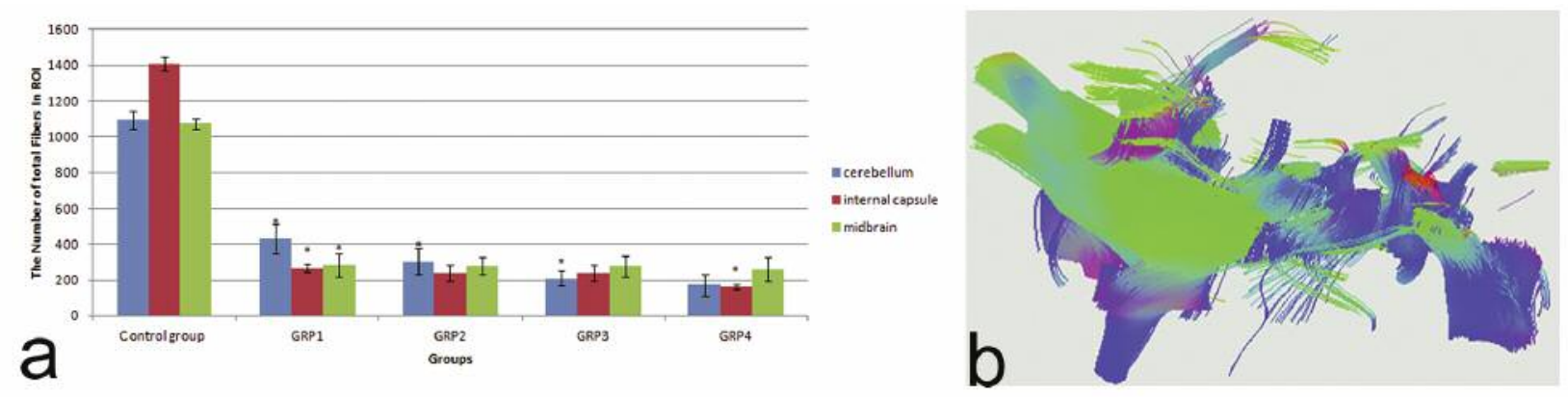

Figure 4. a: Fiber tracking in regions of interest (ROI). The total number of fiber tracts that were tracked in different regions of interest for the same tracking parameters. The number of fiber tracts in the control group was much larger than that in the groups exposed to 1,2-dichloroethane (1,2-DCE). During exposure to 1,2-DCE, there was no significant difference in midbrain between the groups. b: The streamline diffusion tensor tractography of the regions of interest in the control group. *Significantly different compared to the previous group. 
Table II. Analysis of variance results of mean fractional anisotropy (FA) values for different regions of interest (ROI). F and p-values are provided where there was a significant difference in the ROI $(p<0.05)$.

\begin{tabular}{|c|c|c|c|c|c|c|c|c|c|c|}
\hline \multirow[b]{2}{*}{ ROI } & \multicolumn{5}{|c|}{ Mean $\mathrm{FA} \pm \mathrm{SD}$} & \multicolumn{2}{|c|}{ Duration effect } & \multicolumn{2}{|c|}{ Dose effect } & \multirow{2}{*}{$\begin{array}{c}\text { Duration } \times \\
\text { dose-effect } \\
\text { F-Value } p \text {-Value }\end{array}$} \\
\hline & Control group & Group 1 & Group 2 & Group 3 & Group 4 & F-Value & $p$-Value & F-Value & $p$-Value & \\
\hline \multirow[t]{2}{*}{ Internal capsule } & $0.34 \pm$ & $0.32 \pm$ & $0.32 \pm$ & $0.32 \pm$ & $0.31 \pm$ & & & 9.20 & 0.0010 & \\
\hline & $2.67 \mathrm{E}-03$ & $1.52 \mathrm{E}-02$ & $2.14 \mathrm{E}-02$ & 4.34E-03 & $9.26 \mathrm{E}-03$ & & & & & \\
\hline \multirow{2}{*}{$\begin{array}{l}\text { Midbrain-periaqueductal } \\
\text { GM }\end{array}$} & $0.29 \pm$ & $0.28 \pm$ & $0.27 \pm$ & $0.26 \pm$ & $0.26 \pm$ & & & 4.35 & 0.0240 & \\
\hline & $2.84 \mathrm{E}-03$ & $2.75 \mathrm{E}-02$ & $1.23 \mathrm{E}-02$ & $6.20 \mathrm{E}-03$ & 8.77E-03 & & & & & \\
\hline \multirow[t]{2}{*}{ Hypothalamus } & $0.31 \pm$ & $0.27 \pm$ & $0.25 \pm$ & $0.25 \pm$ & $0.25 \pm$ & 6.61 & 0.0165 & 14.40 & 0.0001 & \\
\hline & $9.50 \mathrm{E}-05$ & $9.98 \mathrm{E}-03$ & $8.98 \mathrm{E}-03$ & $9.79 \mathrm{E}-03$ & 7.61E-03 & & & & & \\
\hline \multirow{2}{*}{$\begin{array}{l}\text { Cerebellum- } \\
\text { cerebellar nucleus }\end{array}$} & $0.29 \pm$ & $0.27 \pm$ & $0.25 \pm$ & $0.24 \pm$ & $0.24 \pm$ & & & 5.47 & 0.0107 & \\
\hline & $6.20 \mathrm{E}-03$ & $2.46 \mathrm{E}-02$ & $1.21 \mathrm{E}-02$ & $3.92 \mathrm{E}-03$ & $9.24 \mathrm{E}-03$ & & & & & \\
\hline \multirow[t]{2}{*}{ Cingulate gyrus } & $0.28 \pm$ & $0.24 \pm$ & $0.21 \pm$ & $0.22 \pm$ & $0.21 \pm$ & 12.00 & 0.0019 & 34.97 & 0.0000 & \\
\hline & 4.88E-03 & $1.99 \mathrm{E}-02$ & $1.12 \mathrm{E}-02$ & $3.51 \mathrm{E}-03$ & $2.35 \mathrm{E}-02$ & & & & & \\
\hline \multirow[t]{2}{*}{ Hippocampus } & $0.23 \pm$ & $0.20 \pm$ & $0.20 \pm$ & $0.19 \pm$ & $0.19 \pm$ & & & & & \\
\hline & $1.01 \mathrm{E}-02$ & $2.04 \mathrm{E}-02$ & $2.59 \mathrm{E}-02$ & $3.38 \mathrm{E}-02$ & $1.40 \mathrm{E}-02$ & & & & & \\
\hline \multirow[t]{2}{*}{ Sensory cortex } & $0.26 \pm$ & $0.22 \pm$ & $0.19 \pm$ & $0.19 \pm$ & $0.19 \pm$ & 5.03 & 0.0341 & 3.70 & 0.0391 & \\
\hline & $2.15 \mathrm{E}-04$ & $1.08 \mathrm{E}-02$ & $5.62 \mathrm{E}-03$ & 4.12E-03 & $8.36 \mathrm{E}-03$ & & & & & \\
\hline \multirow[t]{2}{*}{ Motor cortex } & $0.28 \pm$ & $0.25 \pm$ & $0.23 \pm$ & $0.23 \pm$ & $0.23 \pm$ & & & 15.10 & 0.0001 & \\
\hline & $5.95 \mathrm{E}-04$ & $1.86 \mathrm{E}-02$ & $1.23 \mathrm{E}-02$ & $6.07 \mathrm{E}-03$ & $8.76 \mathrm{E}-03$ & & & & & \\
\hline
\end{tabular}

GM: Gray matter.

In the hypothalamus, the FA and ADC showed both a time-and dose-dependent effect of 1,2-DCE. This is in accordance with the literature in which it is reported that there would be an immune response in the hypothalamus in the case of toxic exposure (17).

FA and ADC have been used as biomarkers of tissue integrity in WM and GM, and changes in FA have been attributed to pathological changes in the WM (21). The mean ADC is typically used to assess the microstructural integrity of GM. The integrity of WM is typically assessed with both mean FA and ADC owing to anisotropic diffusion (7).

Compared to the control group, FA and ADC values were mostly decreased in groups exposed to 1,2-DCE. These changes may reflect axonal damage in the experimental groups (22). ADC represents water movement within tissue, and an acute reduction in ADC in experimental groups likely reflects trauma-induced cytotoxic edema and inflammation.

Compared to group 3, an elevated ADC and decreased FA value in group 4 are thought to reflect progressive loss of barriers restricting the motion of water molecules in tissue compartments associated with neuronal loss and disruption of myelin sheaths (9). This may indicate the formation of vasogenic edema in WM and axonal injury (22).

We found that 1,2-DCE exposure had a strong effect on the number of observed fiber tracts. The decrease in FA might be one of the reasons for the lower number of fiber tracts observed in the experimental groups. This decrease in the total number of fiber tracts was even observed for the group with the lowest 1,2-DCE exposure, suggesting that 1,2-DCE can cause acute effects on rat brain with as title as only $1.5 \mathrm{~h}$ of exposure at a concentration of $4 \mathrm{~g} / \mathrm{m}^{3}$.

Our results are consistent with the dynamic changes provided by Zhan et al. (3). These results indicate that primarily cytotoxic edema occurred as a result of 1,2-DCE exposure $(4,23)$. A disturbance of energy metabolism can contribute to the reduction of the ADC via cell swelling (23). Cerebral edemas likely formed in the presence of an intact blood-brain barrier (BBB) while transendothelial secretion of $\mathrm{Na}^{+}, \mathrm{Cl}^{-}$and water into the brain was greatly increased (24).

Vasogenic edema occurs when there is a breakdown of the tight endothelial junctions of the BBB. In cytotoxic edema, the $\mathrm{BBB}$ remains intact and there is swelling of astrocytes with corresponding reduction in extracellular space (25). We predict that with greater 1,2-DCE exposure, damage to the $\mathrm{BBB}$ would be more severe.

In summary, we have successfully created a dynamic rat model of 1,2-DCE poisoning. Our results show that 1,2-DCE exposure leads to changes in FA, ADC and the number of fiber tracts. Primarily cytotoxic edema occurred as a result of 1,2-DCE exposure. dMRI could be used for early noninvasive detection of 1,2-DCE-induced encephalopathy.

\section{Conflicts of Interest}

There is no conflict of interest in regard to this study. 


\section{Acknowledgements}

The cooperation of the Department of Toxicology at the School of Public Health, Central-South University is highly appreciated, without which our animal model would not have been completed. We also thank Dr. Fan Weilin at Tianjin Hope Industry\&Trade Co. Ltd for the service support of our dynamic inhalation chamber.

\section{References}

1 1,2-Dichloroethane. IARC: Monographs on the Evaluation of Carcinogenic Risks to Humans 71: 501-522, 1999. Available from: http://monographs.iarc.fr/ENG/Monographs/vol71/mono 71-21.pdf

2 Liu J-R, Fang S, Ding M-P, Chen Z-C, Zhou J-J, Sun F, Jiang B and Huang J: Toxic encephalopathy caused by occupational exposure to 1,2-dichloroethane. J Neurol Sci 292(1-2): 111-113, 2010 .

3 Zhan F, Zheng W, Liu L and Kong L: Diagnosis and prognosis evaluation of 1,2-dichloroethane encephalopathy - magnetic resonance imaging combined with diffusion tensor imaging and magnetic resonance spectroscopy study. Neurol India 59(1): 108110, 2011.

4 Wang G, Yuan Y, Zhang J, Gao L, Tan X, Yang G, Lv X and Jin $Y$ : Roles of aquaporins and matrix metalloproteinases in mouse brain edema formation induced by subacute exposure to 1,2dichloroethane. Neurotoxicol Teratol 44: 105-112, 2014.

5 Zhou X, Zhou W, Zhou J, Long L and Xiao B: 1,2Dichloroethane-induced toxic leukoencephalopathy with a brain biopsy. Neurol Sci 36: 817-819, 2014.

6 Rosman Y, Eisenkraft A, Krivoy A, Schein O, Makarovski I, Shrot S, Ramaty E, Shilderman E, Kapon J, Gilat E, Kadar T, Maier S, Daniels D, Shneor R, Salomon S, Tamar G, Last D and Mardor Y: Using MRI for the assessment of paraoxon-induced brain damage and efficacy of antidotal treatment. J Appl Toxicol 32: 409-416, 2012.

7 Alexander AL, Lee JE, Lazar M and Field AS: Diffusion tensor imaging of the brain. neurotherapeutics. Re-evaluation of some organic chemicals, hydrazine and hydrogen peroxide 4(3): 316329, 2007.

8 Zhang B, Xu Y, Zhu B and Kantarci K: The role of diffusion tensor imaging in detecting microstructural changes in prodromal Alzheimer's disease. CNS Neurosci Ther 20: 3-9, 2014.

9 Schaefer PW, Grant PE and Gonzalez RG: Diffusion-weighted MR imaging of the brain. Radiology 217: 331-345, 2000.

10 American Physiological Society Council: Guiding Principles for the Care and Use of Vertebrate Animals in Research and Training. Bethesda, Maryland, 2014. Available from: http:// www.the-aps.org/mm/SciencePolicy/About/Policy-Statements/ Guiding-Principles.html.

11 Chen YH, Wang PP, Wang XM, He YJ, Yao WZ, Qi YF and Tang CS: Involvement of endogenous hydrogen sulfide in cigarette smoke-induced changes in airway responsiveness and inflammation of rat lung. Cytokine 53(3): 334-341, 2011.
12 Jiang H, Zijl PCM van, Kim J, Pearlson GD and Mori S: DtiStudio: resource program for diffusion tensor computation and fiber bundle tracking. Comput Methods Programs Biomed 81(2006): 106-116, 2005.

13 Nie B, Chen K, Zhao S, Liu J, Gu X, Yao Q, Hui J, Zhang Z, Teng G, Zhao C and Shan B: A rat brain MRI template with digital stereotaxic atlas of fine anatomical delineations in paxinos space and its automated application in voxel-wise analysis. Hum Brain Mapp 34(6): 1306-1318, 2013.

14 Fillard P, Toussaint N and Pennec X: MEDINRIA: DT-MRI processing and visualizaion software. Similar Tensor Workshop. Las Palmas; 2006.

15 Agency for Toxic Substances and Disease Registry: Toxicological profile for 1,2-dichloroethane. U.S. Department of Health and Human Services Public Health Service. Atlanta, Georgia; 2001.

16 Hotchkiss J a, Andrus a K, Johnson K a, Krieger SM, Woolhiser MR and Maurissen JP: Acute toxicologic and neurotoxic effects of inhaled 1,2-dichloroethane in adult Fischer 344 rats. Food Chem Toxicol 48(2): 470-481, 2010.

17 Matthews BL: What is Chemical Sensitivity? Chemical Sensitivity: A Guide to Coping with Hypersensitivity Syndrome, Sick Building Syndrome, and Other Environmental Illnesses. Mc Farland\&Co Inc, Jefferson, NC, USA: p. 26, 1992.

18 Sharma P, Eesa M and Scott JN: Toxic and acquired metabolic encephalopathies: mri appearance. Am J Roentgenol 193(3): 879-886, 2009.

19 Sutter R and Kaplan PW: Neuroimaging correlates of acute encephalopathy 30(5): 517-525, 2013.

20 Sood S, Gupta R and Sharma J MJ: MRI spectrum in acute toxic and metabolic encephalopathies. ECR, 2014.

21 Kraus MF, Susmaras T, Caughlin BP, Walker CJ, Sweeney JA and Little DM: White matter integrity and cognition in chronic traumatic brain injury: a diffusion tensor imaging study. Brain 130(Pt 10): 2508-2519, 2007.

22 Newcombe VFJ, Williams GB, Nortje J, Bradley PG, Harding SG, Smielewski P, Coles JP, Maiya B, Gillard JH, Hutchinson PJ, Pickard JD, Carpenter TA and Menon DK: Analysis of acute traumatic axonal injury using diffusion tensor imaging. $\mathrm{Br} \mathrm{J}$ Neurosurg 21(4): 340-348, 2007.

23 Rovaris M, Gass a, Bammer R, Hickman S, Ciccarelli O, Miller D and Filippi M: Diffusion MRI in multiple sclerosis. 2005. Available from: http://discovery.ucl.ac.uk/151794/

24 Chen Y-J, Wallace BK, Yuen N, Jenkins DP, Wulff H and O'Donnell ME: Blood-Brain Barrier KCa3.1 Channels: Evidence for a role in brain $\mathrm{Na}$ uptake and edema in ischemic stroke. Stroke 46: 237-244, 2014.

25 Tasker RC and Acerini CL: Cerebral edema in children with diabetic ketoacidosis: Vasogenic rather than cellular? Pediatr Diabetes 15: 261-270. 2014.

Received September 23, 2016

Revised October 10, 2016

Accepted October 11, 2016 